\title{
Nutrition and the psychoneuroimmunology of postpartum depression
}

\author{
E. R. Ellsworth-Bowers ${ }^{1}$ and E. J. Corwin ${ }^{2 *}$ \\ ${ }^{1}$ University of Colorado Anschutz Medical Campus, 13120 E 19th Avenue, C288-18, Aurora, CO, 80045, USA \\ ${ }^{2}$ Nell Hodgson Woodruff School of Nursing, Emory University, Atlanta, GA, 30322, USA
}

\begin{abstract}
Postpartum depression (PPD) is a relatively common and often severe mood disorder that develops in women after childbirth. The aetiology of PPD is unclear, although there is emerging evidence to suggest a psychoneuroimmune connection. Additionally, deficiencies in $n$ - 3 PUFA, B vitamins, vitamin D and trace minerals have been implicated. This paper reviews evidence for a link between micronutrient status and PPD, analysing the potential contribution of each micronutrient to psychoneuroimmunological mechanisms of PPD. Articles related to PPD and women's levels of $n$-3 PUFA, B vitamins, vitamin D and the trace minerals $\mathrm{Zn}$ and Se were reviewed. Findings suggest that while $n$-3 PUFA levels have been shown to vary inversely with PPD and link with psychoneuroimmunology, there is mixed evidence regarding the ability of $n-3$ PUFA to prevent or treat PPD. B vitamin status is not clearly linked to PPD, even though it seems to vary inversely with depression in non-perinatal populations and may have an impact on immunity. Vitamin D and the trace minerals Zn and Se are linked to PPD and psychoneuroimmunology by intriguing, but small, studies. Overall, evidence suggests that certain micronutrient deficiencies contribute to the development of PPD, possibly through psychoneuroimmunological mechanisms. Developing a better understanding of these mechanisms is important for guiding future research, clinical practice and health education regarding PPD.
\end{abstract}

Key words: Micronutrients: Postpartum depression: Immune system: Inflammation

\section{Introduction}

\section{Overview of postpartum depression and psychoneuroimmunology}

Postpartum depression (PPD) is characterised by sadness, fatigue, irritability and disinterest in life events ${ }^{(1)}$. Women with PPD often experience feelings of guilt, worthlessness and anxiety related to birth and parenting; women may also think of suicide or harm toward the baby. A serious mood disorder comparable with major depressive disorder (MDD), PPD can develop as an extension of postpartum blues or arise independently in a mother whose mood has been stable until that point. The Diagnostic and Statistical Manual of Mental Disorders, Fourth Edition (DSM-IV) Text Revision defines PPD as beginning by 4 weeks after birth. However, in clinical practice many women are not diagnosed until 6 weeks to 3 months postpartum ${ }^{(1)}$, and research studies on PPD often extend the time frame for diagnosis to 6 months or 1 year postpartum (see Tables 1 and 2).

Risk factors for PPD include previous mental illness, recent psychological stress, inadequate social or economic support, and a difficult birth experience ${ }^{(2)}$. Women who are experiencing significant physiological stress may also be at risk for PPD ${ }^{(3-5)}$. However, not all women with these risk factors develop PPD. Thus, a key question is what causes certain women to shift from risk to depressive state? Over time, researchers have investigated that question from psychological, social and physiological perspectives.

The perspective framing the present review is physiological, specifically the field of psychoneuroimmunology (PNI). PNI is the study of how neuroendocrine and/or immune system dysregulation may contribute to the development of depression. Dysregulation of both these systems is acknowledged to have a role in depression for nonpregnant, non-postpartum populations ${ }^{(6,7)}$ and, recently, a psychoneuroimmunological contribution to PPD has been hypothesised as well ${ }^{(3,4,8,9)}$. This hypothesis is based on the inherently inflammatory nature of labour, delivery and postpartum healing ${ }^{(10-13)}$, which in some cases may be exaggerated and may increase the risk of depression.

\section{Nutrition and the psychoneuroimmunology of postpartum depression}

An unexplored component of psychoneuroimmunological research on PPD is how nutritional status contributes

Abbreviations: Abbreviations, COX, cyclo-oxygenase; EPDS, Edinburgh Postpartum Depression Scale; HPA, hypothalamic-pituitary-adrenal; MDD, major depressive disorder; PNI, psychoneuroimmunology; PPD, postpartum depression; $\mathrm{T}_{\mathrm{h}}$, $\mathrm{T}$ helper.

*Corresponding author: Dr Elizabeth J. Corwin, fax +1 404712 9093, email elizabeth.j.corwin@emory.edu 
Table 1. Observational studies of the relationship between $n-3$ PUFA and postpartum depression

\begin{tabular}{|c|c|c|c|c|c|}
\hline Study & $\begin{array}{l}\text { Subjects } \\
\qquad(n)\end{array}$ & Subject characteristics and stated exclusions & $n$-3 PUFA measurement & $\begin{array}{l}\text { Depression } \\
\text { measurement }\end{array}$ & Findings \\
\hline De Vriese et al. $(2003)^{(40) *}$ & 48 & $\begin{array}{l}\text { Singleton pregnancy. No: other psychiatric } \\
\text { disorder, chronic disease, psychotropic } \\
\text { medication use, premature labour, perinatal } \\
\text { infection, Caesarian birth }\end{array}$ & Blood sample at delivery & $\begin{array}{l}\text { SCID interview } \\
\text { between } \\
3 \text { and } 12 \\
\text { months } \\
\text { postpartum }\end{array}$ & $\begin{array}{l}\text { Baseline } n \text {-3 PUFA levels are lower in } \\
\text { women who later develop depression }\end{array}$ \\
\hline Makrides et al. $(2003)^{(41) \star}$ & 380 & No reported characteristics or exclusions & $\begin{array}{l}\text { Blood sample at } 6 \text { months } \\
\text { postpartum }\end{array}$ & $\begin{array}{l}\text { EPDS at } \\
6 \text { months } \\
\text { postpartum }\end{array}$ & $\begin{array}{l}\text { Inverse relationship between DHA levels } \\
\text { and depression }\end{array}$ \\
\hline Otto et al. $(2003)^{(42) *}$ & 112 & $\begin{array}{l}\text { Singleton pregnancy, term delivery. No: other } \\
\text { psychiatric disorder, chronic disease, perinatal } \\
\text { blood transfusion, medications other than } \\
\text { vitamins }\end{array}$ & $\begin{array}{l}\text { Blood samples at } 36 \text { weeks } \\
\text { gestation, delivery, } 32 \text { weeks } \\
\text { postpartum }\end{array}$ & $\begin{array}{l}\text { EPDS at } 32 \\
\text { weeks } \\
\text { postpartum }\end{array}$ & $\begin{array}{l}\text { Inverse relationship between rate of DHA } \\
\text { increase and depression. No relationship } \\
\text { between raw DHA levels and depression }\end{array}$ \\
\hline Browne et al. $(2006)^{(43)}$ & 80 & Primiparous. No reported exclusions & $\begin{array}{l}\text { Blood sample at } 6 \text { months } \\
\text { postpartum. Food surveys } \\
\text { at delivery, } 6 \text { months postpartum }\end{array}$ & $\begin{array}{l}\text { EPDS, BDI-II } \\
\text { within } \\
6 \text { months } \\
\text { postpartum }\end{array}$ & $\begin{array}{l}\text { No association between } n-3 \text { PUFA } \\
\text { status or fish consumption and } \\
\text { depression }\end{array}$ \\
\hline Miyake et al. $(2006)^{(44)}$ & 865 & No reported characteristics or exclusions & $\begin{array}{l}\text { Food survey at time of depression } \\
\text { screening }\end{array}$ & $\begin{array}{l}\text { EPDS between } \\
2-9 \text { months } \\
\text { postpartum }\end{array}$ & $\begin{array}{l}\text { No association between fatty acid } \\
\text { status and depression }\end{array}$ \\
\hline
\end{tabular}

SCID, Structured Clinical Interview for DSM-IV Axis I Disorders; EPDS, Edinburgh Postpartum Depression Scale; BDI-II, Beck Depression Inventory-II.

* Evidence of a relationship. 
Table 2. Treatment studies of the relationship between $n$-3 PUFA and postpartum depression

\begin{tabular}{|c|c|c|c|c|c|}
\hline Study & $\begin{array}{l}\text { Subjects } \\
(n) \text { and study details }\end{array}$ & $\begin{array}{l}\text { Subject } \\
\text { characteristics } \\
\text { and stated } \\
\text { exclusions }\end{array}$ & $n$-3 PUFA measurement & $\begin{array}{l}\text { Depression } \\
\text { measurement }\end{array}$ & Findings \\
\hline $\begin{array}{l}\text { Freeman et al. } \\
\qquad(2006)^{(52) \star}\end{array}$ & $\begin{array}{l}n 16 \text {; length: } 8 \text { weeks; treatment: } 0.5 \text {, } \\
1.4 \text { or } 2.8 \mathrm{~g} n-3 \text { PUFA per d } \\
\text { (EPA:DHA ratio of } 1.5: 1)\end{array}$ & $\begin{array}{l}\text { Age } 15-45 \text { years, current episode of depression } \\
\text { with onset within } 1 \text { month } \\
\text { postpartum. No: psychosis or suicidal } \\
\text { ideation, bipolar disorder, antidepressant use }\end{array}$ & $\mathrm{N} / \mathrm{A}$ & $\begin{array}{l}\text { EPDS and HAM-D }+ \text { at } \\
\text { baseline, treatment } \\
\text { weeks } 1,2,4,6 \\
\text { and } 8\end{array}$ & $\begin{array}{l}\text { Treatment associated } \\
\text { with decrease in } \\
\text { depression, but no } \\
\text { variance with dosage }\end{array}$ \\
\hline $\begin{array}{l}\text { Su et al. } \\
\quad(2008)^{(51) *}\end{array}$ & $\begin{array}{l}n \text { 40; length: } 8 \text { weeks; treatment: } 1.2 \mathrm{~g} \\
\text { DHA }+2 \cdot 2 \mathrm{~g} \text { EPA per d }\end{array}$ & $\begin{array}{l}\text { Age } 18-40 \text { years, current episode of depression } \\
\text { with onset at } 16-32 \text { weeks } \\
\text { gestation. No: other psychiatric } \\
\text { disorder, psychotropic medication in } \\
\text { previous month }\end{array}$ & $\begin{array}{l}\text { Blood samples at lead-in } \\
\text { and treatment week } 8\end{array}$ & $\begin{array}{l}\text { HAM-D, EPDS, BDI at } \\
\text { lead-in, baseline, } \\
\text { treatment weeks } 2 \text {, } \\
4,6 \text { and } 8\end{array}$ & $\begin{array}{l}\text { Treatment associated } \\
\text { with decrease in } \\
\text { depression at weeks } \\
6 \text { and } 8\end{array}$ \\
\hline $\begin{array}{l}\text { Llorente et al. } \\
\qquad(2003)^{(45)}\end{array}$ & $\begin{array}{l}n 138 \text {; length: first } 4 \text { months } \\
\text { postpartum; treatment: } 200 \mathrm{mg} \\
\text { DHA per d }\end{array}$ & $\begin{array}{l}\text { Age } 18-42 \text { years, gravida }<5 \text {, planning to } \\
\text { breastfeed. No: chronic disease, } \\
\text { smoking, dietary supplements other } \\
\text { than vitamins }\end{array}$ & $\begin{array}{l}\text { Blood samples in late } 3 \text { rd } \\
\text { trimester and at } 4 \text { months } \\
\text { postpartum }\end{array}$ & $\begin{array}{l}\text { BDI late } 3 \text { rd trimester, } \\
3 \text { weeks, } 2 \text { months, } \\
4 \text { months postpartum }\end{array}$ & $\begin{array}{l}\text { Treatment associated } \\
\text { with increased DHA, } \\
\text { but not depression }\end{array}$ \\
\hline $\begin{array}{l}\text { Freeman et al. } \\
\qquad(2008)^{(48)}\end{array}$ & $\begin{array}{l}n 59 \text {; length: } 8 \text { weeks; treatment: } 1.1 \mathrm{~g} \\
\text { EPA }+0.8 \mathrm{~g} \text { DHA per d; all partici- } \\
\text { pants received psychotherapy }\end{array}$ & $\begin{array}{l}\text { Age } 18-45 \text { years, current episode of depression, } \\
12-32 \text { weeks gestation or } 0-6 \text { months } \\
\text { postpartum. No: active } \\
\text { psychosis or suicidal ideation, bipolar } \\
\text { disorder, antidepressant or anticoagulation } \\
\text { use, substance abuse }\end{array}$ & $\mathrm{N} / \mathrm{A}$ & $\begin{array}{l}\text { EPDS, HAM-D, CGI } \\
\text { every } 2 \text { weeks for } 8 \\
\text { weeks }\end{array}$ & $\begin{array}{l}\text { No relationship between } \\
\text { treatment and } \\
\text { depression }\end{array}$ \\
\hline $\begin{array}{l}\text { Rees et al. } \\
\qquad(2008)^{(49)}\end{array}$ & $\begin{array}{l}n \text { 26; length: } 6 \text { weeks; treatment: } 0.4 \mathrm{~g} \\
\text { EPA + } 1.6 \mathrm{~g} \text { DHA per d }\end{array}$ & $\begin{array}{l}\text { Age }>21 \text { years, current episode of depression, } \\
\text { 3rd trimester-6 weeks } \\
\text { postpartum. No: other psychiatric disorder, } \\
\text { chronic disease, antidepressant or } \\
\text { anticoagulant use, high dietary fish intake, } \\
\text { participation in psychotherapy }\end{array}$ & $\mathrm{N} / \mathrm{A}$ & $\begin{array}{l}\text { EPDS weekly during } \\
\text { treatment period }\end{array}$ & $\begin{array}{l}\text { No relationship between } \\
\text { treatment and } \\
\text { depression }\end{array}$ \\
\hline $\begin{array}{l}\text { Doornbos et al. } \\
\qquad(2009)^{(46)}\end{array}$ & $\begin{array}{l}n \text { 182; length: enrolment to } 3 \text { months } \\
\text { postpartum; treatment: } 220 \mathrm{mg} \mathrm{DHA} \\
\text { per d, or } 220 \mathrm{mg} \mathrm{DHA}+220 \mathrm{mg} \mathrm{AA} \\
\text { per d }\end{array}$ & $\begin{array}{l}\text { Gravida } 1 \text { or } 2 \text {, singleton pregnancy, } 14-20 \\
\text { weeks gestation. No: diabetes, preterm } \\
\text { delivery, vegetarian or vegan diet }\end{array}$ & $\begin{array}{l}\text { Blood samples at } 16 \text { and } \\
36 \text { weeks gestation. } \\
\text { Food surveys throughout } \\
\text { study }\end{array}$ & $\begin{array}{l}\text { EPDS at } 16 \text { and } 36 \\
\text { weeks gestation, } 6 \\
\text { weeks postpartum }\end{array}$ & $\begin{array}{l}\text { Treatment associated } \\
\text { with increased DHA } \\
\text { and } A A \text {, but not } \\
\text { depression }\end{array}$ \\
\hline $\begin{array}{l}\text { Mattes et al. } \\
\qquad(2009)^{(47)}\end{array}$ & $\begin{array}{l}n \text { 98; length: } 20 \text { weeks gestation to } \\
\text { delivery; treatment: } 2 \cdot 24 \mathrm{~g} \text { DHA } \\
+1 \cdot 1 \mathrm{~g} \text { EPA per } \mathrm{d}\end{array}$ & $\begin{array}{l}\text { Gestation }<20 \text { weeks, diagnosed atopy. } \\
\text { No: other chronic disease, smoking, use of fish } \\
\text { oil supplements or high dietary fish intake }\end{array}$ & $\begin{array}{l}\text { Blood samples at } 20 \text { weeks } \\
\text { gestation, delivery }\end{array}$ & $\begin{array}{l}\text { BDI at } 20 \text { weeks } \\
\text { gestation, delivery }\end{array}$ & $\begin{array}{l}\text { No relationship between } \\
\text { treatment and } \\
\text { depression }\end{array}$ \\
\hline $\begin{array}{l}\text { Makrides et al. } \\
\quad(2010)^{(50)}\end{array}$ & $\begin{array}{l}n \text { 2399; length: enrolment to delivery; } \\
\text { treatment: } 800 \mathrm{mg} \mathrm{DHA}+100 \mathrm{mg} \\
\text { EPA per d }\end{array}$ & $\begin{array}{l}\text { Singleton pregnancy, }<21 \text { weeks gestation. } \\
\text { No: DHA therapy, anticoagulant medication, } \\
\text { bleeding disorder, substance use, known } \\
\text { fetal abnormality }\end{array}$ & $\mathrm{N} / \mathrm{A}$ & $\begin{array}{l}\text { EPDS at } 6 \text { weeks and } \\
6 \text { months } \\
\text { postpartum }\end{array}$ & $\begin{array}{l}\text { No relationship between } \\
\text { treatment and } \\
\text { depression }\end{array}$ \\
\hline
\end{tabular}

N/A, not applicable; EPDS, Edinburgh Postpartum Depression Scale; HAM-D, Hamilton Rating Scale for Depression; BDI, Beck Depression Inventory; CGI, Clinical Global Impressions Scale; AA, arachidonic acid.

Evidence of a relationship.

† This study uses the abbreviation of 'HRSD' for the 'Hamilton Rating Scale for Depression'. 
to the proper function of the innate immune system and hypothalamic-pituitary-adrenal (HPA) axis. In 2005, Bodnar \& Wisner ${ }^{(14)}$ laid the foundation for research in this area by describing a set of micronutrients ( $n-3$ PUFA, B vitamins, trace minerals, antioxidants) that become depleted during pregnancy and perhaps play a role in depression for non-pregnant, non-postpartum populations. Since then, vitamin D has also been implicated as a possible contributor to $\mathrm{PPD}^{(15)}$. The question guiding the present investigation is whether PNI might be a mechanism by which these micronutrients are associated with PPD.

\section{Critical review: micronutrient links to the psychoneuroimmunology of postpartum depression}

This broad review aims to present the current status of research related to nutrition and the PNI of PPD, rather than a detailed summary of a limited number of articles. To this end, we conducted an extensive literature search in PubMed for human studies in English, using combinations of the terms ('inflammation', 'depression', 'post-partum') with ('PUFA', 'poly unsaturated fatty acids', 'omega-3', 'folate', 'B12', 'vitamin D', 'antioxidant', 'anti-inflammatory', 'mineral', 'microelement', 'nutrition'). We also conducted a manual search for papers referenced in articles retrieved through PubMed.

Of the micronutrients that researchers have identified as associated with PPD, the fatty acid literature is the most developed and has the strongest emphasis on postpartum populations. Studies of B vitamins and depression are fewer, with little focus on women's mental health. Studies of the relationship between vitamin D or trace minerals and depression also have a limited focus on postpartum populations. Our searches did not identify any studies linking general antioxidants to psychoneuroimmunological causes of depression, so the present paper will not further discuss antioxidants.

We introduce each micronutrient with a brief overview of its biochemistry and dietary sources. Then, we present and critique evidence for the micronutrient's linkage to PNI and evidence for the micronutrient's role in depression in the general population. This presentation is followed by analysis of the micronutrient's potential role in PPD and evaluation of each micronutrient as a potential subject for psychoneuroimmunological research into the aetiology of PPD.

\section{PUFA}

Two families of essential long-chain PUFA cannot be synthesised by human bodies: $n-3$ and $n-6$ fatty acids ${ }^{(16)}$. Thus, human diets must contain either the $n-3$ and $n-6$ PUFA or their precursor molecules ( $\alpha$-linolenic acid for $n-3$ and linoleic acid for $n-6$ ). $n$-3 PUFA are concentrated in fatty fish and certain algae; their precursor $\alpha$-linolenic acid is concentrated in plant sources such as flaxseed and walnuts. (It is important to note, however, that synthesis of $n$-3 PUFA from $\alpha$-linolenic acid is inefficient. Thus, human consumers rely significantly on seafood for meeting their demands of $n-3$ PUFA.) n-6 PUFA are concentrated in animals that are fed diets high in cultivated cereals; their precursor linoleic acid is concentrated in vegetable oil sources such as maize, soya, sunflower-seed and cottonseed.

Linkage to psychoneuroimmunology. PUFA may influence the PNI of depression through their impact on the immune system's inflammatory response. $n$-3 PUFA function in the body in the form of EPA and a further derivative, DHA. Supplementation with these molecules has been shown to decrease levels of key inflammatory cytokines TNF- $\alpha$, IL-1 $\beta$, IL-6, and IL- ${ }^{(17)}$. Further research investigating mechanisms for the anti-inflammatory effect of $n-3$ PUFA has demonstrated that EPA limits the activation of transcription factor NF- $\mathrm{B}$, a major pathway for the formation of pro-inflammatory cytokines ${ }^{(18)}$.

Another way by which EPA limits inflammation is competitive inhibition of the cyclo-oxygenase (COX) inflammation pathway. The COX pathway converts the body's primary $n$-6 PUFA, arachidonic acid, to pro-inflammatory cytokines such as prostaglandins and prostacyclins. However, high levels of EPA directly impede production of arachidonic acid derivatives by using the COX enzyme to form EPA derivatives instead ${ }^{(17,19)}$.

Role in depression. Since the $1980 \mathrm{~s}$, researchers have reported a protective effect of $n$-3 PUFA against inflammatory conditions such as $\mathrm{CVD}^{(17,20)}$, cancer ${ }^{(21)}$ and autoimmune disease ${ }^{(22,23)}$. Because depression is often co-morbid with these diseases, researchers began asking whether $n-3$ PUFA levels that protect against inflammatory disease might also protect against depression. Early observational studies were remarkably consistent: serum and dietary $n$-3 PUFA levels are low in depressed patients, and countries with lower $n$-3 PUFA consumption have higher rates of depression $^{(24,25)}$.

Following publication of these observations, psychiatric researchers began conducting intervention studies on the effectiveness of $n$ - 3 PUFA supplementation as a treatment for MDD. Multiple studies have shown effectiveness of $n-3$ PUFA supplementation ${ }^{(26-29)}$, but some have shown no change from placebo ${ }^{(30-32)}$. Interpretation of these results is confounded by variance in the dosages and EPA:DHA ratios used in the studies, as well as whether $n-3$ PUFA were a monotherapy or adjunct to anti-depressants and psychotherapy. Variance in the age of study populations also limits generalisability of results. However, because accumulating evidence leaned toward the effectiveness of $n-3$ PUFA supplementation, the American Psychiatric Association recommended in 2006 that practitioners consider $n$-3 PUFA monitoring and supplementation during treatment of mood disorders ${ }^{(33)}$. That recommendation continues to be the standard of care.

Two significant mechanisms have been proposed for the apparent relationship between PUFA and depression. 
The first is a psychoneuroimmunological hypothesis, that by limiting production of pro-inflammatory eicosanoids and cytokines, $n$-3 PUFA prevent the inflammatory state that characterises clinical depression ${ }^{(25,34)}$. The second mechanism is neuronal; $n$-3 PUFA help regulate the production, function and metabolism of serotonergic neurotransmitters ${ }^{(35)}$.

Role in postpartum depression. In the $1990 \mathrm{~s}$, multiple studies characterised maternal depletion of $n$-3 PUFA, particularly DHA, during pregnancy and lactation ${ }^{(36-38)}$. Maternal stores of DHA can reduce by $50 \%$ during pregnancy and not return to pre-pregnancy levels until 6 months postpartum. Then, in 2002, an epidemiological study by Hibbeln linked low maternal $n$-3 PUFA levels with PPD $^{(39)}$. Hibbeln compiled a multinational dataset to compare two measures of maternal n-3 PUFA levels (seafood consumption and breast milk DHA content) with rates of PPD. After establishing the dataset and a conservative threshold for PPD (score of $12 / 13$ on the Edinburgh Postpartum Depression Scale; EPDS), Hibbeln conducted multiple levels of analysis to assess the impact of confounding factors such as socio-economic status, spouse/family support, and geographical latitude/light exposure. Hibbeln demonstrated that both lower rates of seafood consumption and lower concentrations of breast milk DHA were strongly correlated with higher rates of postpartum depressive symptoms.

In the years immediately following publication of Hibbeln's data ${ }^{(39)}$, multiple observational studies were conducted to compare postpartum subjects' $n$-3 PUFA levels with depressive symptoms (Table 1). Three of five studies during this period reported an inverse correlation between $n-3$ PUFA levels and $\operatorname{PPD}^{(40-42)}$, while the other two showed limited or no relationship ${ }^{(43,44)}$. There are no systematic methodological distinctions among the studies that might explain why some showed a relationship and some did not. Areas of consistency in study design are: use of EPDS to assess depression; and use of blood samples rather than diet to assess $n$-3 PUFA levels (four of five studies). Areas of inconsistency in study design are: prospective cohort $v$. cross-sectional design; timeline for assessing n-3 PUFA status and screening for depression; and threshold on the screening tool used for considering a woman 'depressed'.

Since publication of Hibbeln's data ${ }^{(39)}$, eight interventional studies (Table 2) have been published that examine the link between $n-3$ PUFA and perinatal depression (second trimester of pregnancy to 4 months postpartum). The studies are all placebo-controlled, randomised and blinded. Of the eight studies, six report no effect of $n-3$ PUFA supplementation on perinatal depression ${ }^{(45-50)}$, while two studies report an inverse association between $n$-3 PUFA supplementation and perinatal depression ${ }^{(51,52)}$. Yet, as with observational studies of $n$-3 PUFA and PPD, there is no straightforward explanation for these mixed results. An area of consistency in study design is the use of EPDS to assess depression. Areas of inconsistency in study design are: when in the perinatal period intervention occurred; dosage and ratio of EPA:DHA used in treatment; whether blood samples confirmed an impact of $n$-3 PUFA supplementation; sample size; inclusion/exclusion of participants with confounding factors; and timeline for assessing $n$-3 PUFA status and screening for depression.

Assessment of research potential n-3 PUFA and the psychoneuroimmunology of postpartum depression. Recent results from clinical trials have cast doubt on the potential of $n-3$ PUFA to prevent depression for a general postpartum population ${ }^{(50)}$. However, meta-analysis results $^{(53)}$ suggest that $n$-3 PUFA consumption may help prevent PPD for certain ethnic populations, and that specific $n-3$ PUFA may have different effects for prevention than treatment. Thus, it is valuable for research to continue on the relationship between $n-3$ PUFA and PPD. Based on the role of $n-3$ PUFA in modulating inflammation, investigation of psychoneuroimmunological mechanisms for the relationship is one avenue by which research should proceed.

\section{$B$ vitamins}

B vitamins are a family of eight water-soluble molecules that have similar structures and act as enzymes for metabolic processes throughout the body, particularly in the haematological, nervous and integumentary systems. B vitamins are both numbered and named (for example, vitamin $B_{2}$ is 'riboflavin'; vitamin $B_{9}$ is 'folate') and are found in a wide variety of unprocessed foods. Gross deficiencies in B vitamins can cause chronic problems ranging from anaemia (microcytic, vitamin $\mathrm{B}_{6}$; macrocytic, vitamins $B_{9}$ and $B_{12}$ ), to peripheral nervous system impairment (vitamins $B_{1}$ and $B_{12}$ ), to severe psychological disturbance (vitamins $\mathrm{B}_{1}, \mathrm{~B}_{3}, \mathrm{~B}_{6}$ and $\mathrm{B}_{12}$ ).

Linkage to psychoneuroimmunology. The linkage between B vitamins and PNI is limited, as B vitamins do not have a direct influence on the immune system or HPA axis. What $\mathrm{B}$ vitamins do influence are the background levels of cardiovascular inflammation, by managing levels of the pro-inflammatory amino acid homocysteine ${ }^{(54)}$. Vitamins $B_{9}$ and $B_{12}$ convert homocysteine to methionine, an amino acid needed for the translation step of protein synthesis, and vitamin $\mathrm{B}_{6}$ helps condense homocysteine into a precursor of the amino acid cysteine ${ }^{(55,56)}$.

Role in depression. Depression in general populations has been linked to low levels of B vitamins and/or high levels of homocysteine. The implicated $\mathrm{B}$ vitamins vary depending on the study population, such as vitamin $\mathrm{B}_{12}$ showing strong correlation with depression in elder populations ${ }^{(57-59)}$ and vitamin $\mathrm{B}_{9}$ showing correlation with depression in adult and adolescent populations ${ }^{(55,60)}$. Because almost all studies use a cross-sectional design, however, analysis raises the question of whether low B vitamin and high homocysteine levels cause depression, result from depression or are co-morbid with depression. 
Longitudinal studies that would elucidate this relationship have not been conducted. The results of treatment studies using $\mathrm{B}$ vitamins as preventive and adjunctive therapy for depression have been mixed, depending on dosage levels prescribed and participants' general health status ${ }^{(61-63)}$.

In the absence of evidence clarifying the relationship between $\mathrm{B}$ vitamins and depression, causal mechanisms have been proposed but not thoroughly investigated. A neuronal hypothesis suggests that low levels of vitamins $\mathrm{B}_{6}, \mathrm{~B}_{9}$ and $\mathrm{B}_{12}$ might cause decreased synthesis of the neurotransmitters serotonin, dopamine and noradrenaline ${ }^{(62,64)}$. A second, 'vascular hypothesis' of depression suggests that B vitamin deficiency allows hyperhomocysteinaemia, which in turn is associated with vascular damage and a state of chronic inflammation. In addition, damage to the carotid and intracerebral arteries can cause persistently low $\mathrm{O}_{2}$ delivery to the prefrontal cortex, resulting in depression and generally poor mentation. However, research in recent years has suggested that hyperhomocysteinaemia may be co-morbid with CVD rather than a cause of it ${ }^{(54,57)}$, calling into question the vascular hypothesis for how B vitamin deficiency relates to depression.

Role in postpartum depression. Few studies have investigated the relationship between $\mathrm{B}$ vitamins and PPD, and those that have do not provide evidence of a likely link. In an early prospective cohort study ( $n$ 131), Rouillon et al. recorded serum vitamin $\mathrm{B}_{9}$ status on the third day postpartum and measured PPD at 1,2 and 3 months postpartum ${ }^{(65)}$. The authors found no correlation between vitamin $\mathrm{B}_{9}$ status and PPD. Later, Miyake et al. ${ }^{(64)}$ used a FFQ to characterise dietary intake of vitamins $\mathrm{B}_{2}, \mathrm{~B}_{6}$, $\mathrm{B}_{9}$ and $\mathrm{B}_{12}$ in a prospective cohort of 865 women. The only inverse association identified between $\mathrm{B}$ vitamin intake and PPD occurrence (measured between 2 and 9 months postpartum) was between vitamin $\mathrm{B}_{2}$ and PPD. However, this inverse relationship was only significant $(\mathrm{CI}=95 \%)$ for the third quartile of vitamin $\mathrm{B}_{2}$ consumption.

Assessment of research potential: $B$ vitamins and the psychoneuroimmunology of postpartum depression. Currently, there is no strong evidence correlating B vitamin levels with PPD. Much work remains to characterise a possible link between B vitamins and PPD, particularly longitudinal research that measures levels of vitamins $B_{2}$, $\mathrm{B}_{6}, \mathrm{~B}_{9}$ and $\mathrm{B}_{12}$ throughout the postpartum period. In addition, $\mathrm{B}$ vitamins do not have an identified neuroendocrine or immune function through which $\mathrm{B}$ vitamin deficiency might contribute to the PNI of PPD. Thus, we hesitate to recommend research on $\mathrm{B}$ vitamins and the PNI of PPD.

\section{Vitamin D}

Vitamin D is a steroid hormone synthesised by the skin in response to UVB light. To become biologically active, the molecule undergoes a first hydroxylation reaction in the liver. Then, specialised cells in the kidneys, brain and immune system complete a second hydroxylation reaction, creating the body's functional form of vitamin D, calcitriol $^{(66,67)}$. Dietary sources of vitamin D include fortified dairy or cereal products, fatty fish, eggs and beef liver.

Vitamin D works at a cellular level by activating the vitamin D nuclear receptor. Genes under the influence of the vitamin D nuclear receptor contribute to Ca transport, bone remodelling, cell cycling, cell differentiation and apoptosis. While vitamin D's role in Ca regulation and bone health has long been recognised, its role in cellular proliferation and development has been a subject of increasing interest over the last 10 years ${ }^{(66)}$.

Linkage to psychoneuroimmunology. Vitamin D exerts influence over both cellular and humoral immune responses. Early animal studies showed that vitamin D inhibits CD4 and $\mathrm{T}$ helper $\left(\mathrm{T}_{\mathrm{h}}\right)$ cell activation in autoimmune disease models ${ }^{(68)}$. Later studies produced more specific findings, indicating that vitamin $\mathrm{D}$ shifts the body's production of $\mathrm{T}$ lymphocytes away from $T_{h} 1$ toward $T_{h} 2$ cells. As a result, $\mathrm{T}_{\mathrm{h}} 1$ production of inflammatory cytokines interferon- $\gamma$ and IL-2 decreases, while $\mathrm{T}_{\mathrm{h}} 2$ production of cytokines such as IL-4, IL-5 and IL-10 increases. These cytokines in turn stimulate B cell production ${ }^{(67)}$. Vitamin D also decreases NF-кB activation of macrophages, thereby reducing macrophage production of pro-inflammatory cytokines ${ }^{(67)}$.

In addition to impacts on the immune system, vitamin D interacts with elements of the HPA axis. In hippocampal cells cultured from young rats, researchers have examined the interaction between vitamin $\mathrm{D}$ and glucocorticoids ${ }^{(69)}$. Normally, glucocorticoids prevent the differentiation of hippocampal cells, and if glucocorticoids stimulate the cells for extensive periods, apoptosis occurs. However, vitamin D exerts two effects on this glucocorticoid system: when applied to hippocampal cells concurrently with glucocorticoids, it allows morphological changes in the cells; when applied to hippocampal cells before long-term glucocorticoid exposure, it significantly decreases the extent of apoptosis.

Role in depression. Four cross-sectional studies in nonpsychiatric populations have examined the relationship between vitamin D levels and depression. Of these, three found that a low serum vitamin D level was associated with depressive symptoms ${ }^{(70-72)}$. However, in a study of similar sample size and design, researchers found no association between vitamin D levels and depression ${ }^{(73)}$. Other cross-sectional studies have examined vitamin D levels in patients already identified with depression, comparing those depressed patients with non-depressed controls. Three of these studies identified a low vitamin Ddepression link ${ }^{(74-76)}$, while two other studies found no significant difference in vitamin D status between depressed and non-depressed patients ${ }^{(77,78)}$.

Two double-blind, randomised treatment trials have specifically examined the relationship between vitamin D and depression. In a 1-year-long prospective study in an overweight/obese population, researchers found significant improvement in depressive symptoms with ongoing, 
high-level supplementation of vitamin $\mathrm{D}^{(79)}$. The other treatment study used a very different design, investigating whether annual oral administration of high-level, singledose vitamin D could make an impact on $\operatorname{mood}^{(80)}$. (The rationale for single-dose administration was its reported effectiveness as a treatment for seasonal affective disorder.) However, the study found no prevention effect for depressive symptoms between the treatment and control groups.

Three general concerns limit interpretation of research on vitamin $\mathrm{D}$ and depression. As discussed in regard to studies of B vitamins, cross-sectional designs do not support a distinction among cause/effect/co-morbid relationships. Next, most of these studies failed to adjust for other factors known to influence depression, such as smoking, CVD and diet/exercise. Finally, many of these studies focused on middle-aged or older adults. Patterns and mechanisms of depression in elder populations cannot be assumed to be consistent across the lifespan.

The studies discussed above have generated significant interest in the relationship between vitamin $\mathrm{D}$ and depression. However, researchers have proposed few hypothetical mechanisms for the low vitamin Ddepression relationship. The dominant hypothesis in the literature is neuronal, focusing on vitamin D's influence on hypothalamus function and the production of neurotransmitters ${ }^{(71,81,82)}$. To our knowledge, a psychoneuroimmunological hypothesis has been mentioned only briefly, even though vitamin D's contribution to immune function is well established ${ }^{(15,82)}$.

Role in postpartum depression. One study has investigated the association between vitamin $\mathrm{D}$ and PPD. Researchers monitored vitamin D levels and depressive symptoms for ninety-seven women on a monthly basis for 7 months ${ }^{(15)}$. Using a dichotomous model with a cut-off score of 9 on the EPDS and $32 \mathrm{ng} / \mathrm{ml}$ vitamin $\mathrm{D}$, depression was consistently higher for women with lower vitamin D levels than higher vitamin D levels. Limitations of the study include its use of a convenience sample, no participant exclusions for other factors influencing depression (social support, etc.) and no clinical assessment of depression following screening with the EPDS.

Assessment of research potential: vitamin $D$ and the psychoneuroimmunology of postpartum depression. The contributions of vitamin D to immune and HPA axis function suggest that vitamin $\mathrm{D}$ could be an appropriate focus for PNI of PPD research. However, because the only research linking vitamin D to PPD is a small pilot study, any investigation of vitamin D's link to the PNI of PPD needs to begin with extensive characterisation of the vitamin D-PPD relationship.

\section{Trace minerals}

Dietary minerals are elements present in the human body that are not common components of organic molecules. Some dietary minerals occur in relatively large quantities and play structural $(\mathrm{Ca})$ and electrolyte $(\mathrm{Na}, \mathrm{K}, \mathrm{Cl})$ roles. Other dietary minerals occur in trace amounts and function as enzymic cofactors and cell-signalling molecules. Food sources for dietary minerals vary widely. Some are concentrated in animal products $(\mathrm{Fe}, \mathrm{Ca}, \mathrm{P})$, while others are concentrated in vegetarian sources $(\mathrm{K}, \mathrm{Mg})$.

If no supplements are consumed and excretion mechanisms function adequately, the human body rarely reaches a toxic concentration of minerals. Mineral deficiency, however, is common. Humans can become deficient in dietary minerals due to inadequate intake, overactive bladder or bowel excretion, or a pathogenic body condition (for example, low Fe due to chronic bleeding). In addition, women's bodies can become depleted of minerals during pregnancy and lactation, due to transfer of minerals to the fetus and infant. When deficiencies occur, symptoms vary according to the mineral and to the level of deficiency.

Of specific interest for the present study are the trace minerals $\mathrm{Zn}$ and Se. Both minerals play multiple roles throughout the body (particularly as enzyme cofactors and by contributing to the structure of amino acids), and both minerals have been associated with depression ${ }^{(83,84)}$. Both minerals can be ingested in adequate amounts from a well-rounded diet; $\mathrm{Zn}$ is particularly concentrated in red meat, seeds and beans, while Se is concentrated in nuts, meat and fish. In the sections below, we discuss each mineral in turn.

Linkage to psychoneuroimmunology. Zn deficiency has been linked to immunosuppression through treatment studies, prevention studies and laboratory studies of animal models ${ }^{(84-86)}$. One mechanism by which $\mathrm{Zn}$ deficiency contributes to immunosuppression is altering the balance between pro- and anti-inflammatory cytokines ${ }^{(87)}$, such as allowing greater production of NF- $\kappa \mathrm{B}^{(87)}$ and IL-1 ${ }^{(88)}$. A second mechanism by which Zn deficiency causes immunosuppression is altering the number and productivity of $\mathrm{B}$ cells and $\mathrm{T}$ cells, a process that possibly involves the HPA axis ${ }^{(89)}$

Se's primary function in the immune system is antiinflammatory, mediated by the selenoprotein glutathione peroxidase $^{(83,90)}$. A key antioxidant with variants across species, glutathione peroxidase reduces $\mathrm{H}_{2} \mathrm{O}_{2}$ and thus limits the COX pathway production of pro-inflammatory cytokines. Se also contributes to cellular immunity by stimulating $\mathrm{T}$ cell clonal expansion and potentiating the action of natural killer cells (first identified in $1994^{(91)}$, now a foundation for Se research in virology ${ }^{(92,93)}$ and oncology ${ }^{(94-98)}$ ).

Role in depression. Low levels of $\mathrm{Zn}$ have been linked to mood disorders since the $1980 \mathrm{~s}$. This relationship has been consistent for populations of different ages, from young adult ${ }^{(99)}$ to adult ${ }^{(100)}$ to elderly ${ }^{(101)}$. Some studies even support a tentative relationship between $\mathrm{Zn}$ and mood regulation in infants and young children ${ }^{(102)}$. Yet, it is important to note that longitudinal studies have not yet been conducted that would clarify a cause/effect/ co-morbid relationship between $\mathrm{Zn}$ and depression. 
In the absence of longitudinal data, treatment studies are one way to elucidate the $\mathrm{Zn}$-depression relationship. Nowak et al. reported results from a small ( $n$ 20) doubleblind, placebo-controlled study of $\mathrm{Zn}$ as an adjunct to standard antidepressant therapy in a non-hospitalised adult MDD population ${ }^{(103)}$. Depressive symptoms after 6 and 12 weeks of treatment were reduced in those receiving both $\mathrm{Zn}$ supplements and antidepressant medication, compared with the control group receiving placebos and antidepressants. Later, Sawada \& Yokoi $^{(99)}$ tentatively expanded these findings to a non-MDD population. Sawada \& Yokoi's small ( $n$ 31) double-blind, placebocontrolled pilot study tested the impact of Zn supplementation on the mood of healthy young adult women. Results showed a significant decrease in anger-hostility and depression-dejection scores, but no significant changes in other mood components (for example, tension-anxiety, vigour, fatigue and confusion).

Efforts to understand the mechanisms by which $\mathrm{Zn}$ deficiencies might contribute to depression have focused on neuronal hypotheses; $\mathrm{Zn}$ has not yet received attention from the PNI research community. The neuronal hypotheses are based on evidence that half of the brain's free $\mathrm{Zn}$ is stored in synaptic vesicles of hippocampal glutamatergic neurons. Physiologically normal levels of $\mathrm{Zn}$ may regulate glutamate release from these neurons ${ }^{(104)}$, protecting neuron health in an area of the brain whose atrophy has been linked to mood disorders ${ }^{(105)}$.

The relationship between low Se levels and depression has primarily been explored through treatment studies. In the $1980 \mathrm{~s}$, Se was part of three antioxidant interventions for geriatric populations ${ }^{(106)}$. In these studies, subjects treated for up to 1 year with combinations of Se and other antioxidants (vitamins A, C and E) showed improvement in measures of mood and cognitive function. However, the studies did not allow specific impacts of Se to be identified. Then, in 1991, Benton \& Cook ${ }^{(106)}$ reported research investigating whether Se supplementation alone would make an impact on mood. Results of that placebo-controlled, double-blind study involving fifty subjects indicate that Se supplementation causes significant improvement in mood only for subjects with a low baseline Se level, and minimal or no change in mood for subjects whose baseline Se status is marginal or adequate. However, these minimal impacts were not observed in a later, very small $(n 11)$ study ${ }^{(107)}$.

In 1998, Finley \& Penland ${ }^{(108)}$ identified the most significant treatment effect to date for Se's impact on mood. In this study ( $n$ 30), subjects consuming a prescribed high-Se diet (utilising pastured meat and grains raised in high-Se soil) showed increased plasma Se and reported less mood disturbance over time than those consuming a low-Se diet. The result was robust across multiple subscale measures of mood (elated-depressed, composed-anxious, etc.). However, participants in the study's treatment groups did not have similar baseline mood scores; the high-Se group had a higher number of participants with baseline mood disturbance. Thus, the question must be asked whether Se is particularly helpful for individuals already experiencing disturbed mood, or whether Se can limit mood disturbance in the general population.

As a follow-up to these intervention studies, in 2006 Rayman et al. included a mood assessment protocol in their pilot ( $n$ 501) for the UK PRECISE study (UK PREvention of Cancer by Intervention with SElenium) ${ }^{(109)}$. The pilot study was a 6-month, double-blind, randomised trial for Se supplementation in otherwise healthy older adults (age 60-74 years). The study found no relationship between mood and Se supplementation status.

Mechanisms by which Se deficiency might contribute to depression have been proposed but not explored. One idea is that, due to selenoprotein glutathione peroxidase's role in processing thyroid $\mathrm{H}_{2} \mathrm{O}_{2}$, Se deficiency may make an impact on mood by decreasing thyroid function ${ }^{(110)}$ A neuronal explanation of the Se-depression link is based on evidence that Se concentration influences dopamine metabolism ${ }^{(111)}$; however, animal studies suggest that only severe Se deficiency is likely to make an impact on dopamine levels ${ }^{(109)}$. To our knowledge, a psychoneuroimmunological mechanism for a Se-depression link has not yet been proposed in the literature.

Role in postpartum depression. One study has investigated the association between $\mathrm{Zn}$ and PPD. Working with a cohort of sixty-six women, all of whom were receiving $\mathrm{Zn}$ supplements, Wójcik et al. measured serum $\mathrm{Zn}$ and screened for depression at three points in time: 1 month before delivery, $3 \mathrm{~d}$ postpartum and $30 \mathrm{~d}$ postpartum ${ }^{(112)}$. Wójcik et $a l .{ }^{(112)}$ was able to support in a postpartum population the earlier conclusion of Maes et al. ${ }^{\text {(113) }}$ for adult MDD: Zn levels vary inversely, along a continuous spectrum, with the severity of depressive symptoms.

One study likewise has investigated the relationship between Se and PPD. Mokhber et al. ${ }^{(114)}$ reported the results of a placebo-controlled, randomised, double-blind Se supplementation trial ( $n$ 218) during the last 6 months of pregnancy. Pre-/post-treatment serum Se was measured, and screening for PPD occurred 8 weeks after delivery. Results demonstrated a significant increase in serum Se in the treatment group, indicating that low Se levels are responsive to intervention. Mokhber et al. also reported that mean depression scores were significantly lower in women receiving Se supplementation, even after thorough analysis of social support factors.

Assessment of research potential: trace minerals and the psychoneuroimmunology of postpartum depression. In conclusion, the trace minerals $\mathrm{Zn}$ and Se are an appropriate focus for PNI of PPD research. However, the research on trace minerals and MDD that would support a PNI of PPD investigation is in its infancy. Thus, it is unlikely that research on the PNI of PPD would make significant progress toward understanding $\mathrm{Zn}$ and Se's contributions to PPD unless concurrent work occurs on the biochemical aspects of how trace minerals relate to MDD. 


\section{Discussion}

We have reviewed evidence linking women's micronutrient status to the development of PPD, focusing on the potential contribution of micronutrient status to a psychoneuroimmunological mechanism of PPD. Although data regarding a micronutrient-PPD link and PNI of PPD mechanism are provocative, available evidence cannot support strong conclusions in either area. The strength of conclusions is limited by two factors. First, for each micronutrient of concern, studies have produced conflicting results - yet meta-analysis to resolve these conflicts is not possible because the studies vary so greatly in design (for example, definitions of depression, measurement of micronutrient status, guidelines for participant exclusion). Thus, researchers and clinical practitioners have no formal tool to assess the balance of evidence for or against a micronutrient-PPD link. Second, the studies were not designed to test particular mechanisms for how each micronutrient could contribute to PPD. Thus, conclusions for any single study are limited to a statement for or against the micronutrient-PPD link, offering no further insight about how the micronutrient may relate to PPD. Without consideration of a mechanism of action, studies have not been structured to identify special conditions under which a relationship might exist, such as in particular patient populations (history of mental illness, inflammatory disease, limited social support), according to the degree of micronutrient deficiency (before, during, after pregnancy) or according to the type of micronutrient consumed (dietary, supplement, pharmaceutical-grade, etc.).

In light of these limitations in the body of literature on micronutrients and PPD, we propose three principles to guide future investigations. First, studies conducted by various research groups need to comply with more stringent design recommendations (see below). Meeting these standards will enable the findings of future studies to be compiled into meta-analysis projects. Second, studies need to investigate underlying mechanisms about a micronutrient's relationship with PPD. This will help tease out the aetiology of each micronutrient's contribution, if any. By better understanding the aetiology, we can better investigate the conditions in which the micronutrient is likely to exert significant impact. Then, we can design more effective interventions for women at risk of PPD. Finally, researchers are encouraged to keep in mind that single-nutrient interventions generally have less impact on mood than broad-spectrum nutritional interventions (prescribed diet, nutritional counselling, etc.). Singlenutrient interventions may even have negative effects, such as recent evidence that fish oil supplements for lactating women may be associated with decreased cognitive abilities in children at 7 years of age ${ }^{(115)}$. Thus, future research needs to build a picture of how multiple micronutrients contribute to PPD.

\section{Research design recommendations}

Research designs should take into account several considerations. First, research needs adequate sample size and ethnically diverse patient populations. Working from the perspective of the PNI of PPD, patients with histories of immune disorders or inflammatory diseases should not be included, as these patients' basic inflammatory milieu is significantly different from the general population.

Second, if possible, research should be longitudinal. This prevents the cause/effect/co-morbid uncertainty inherent in cross-sectional research. This is especially important from a PNI of PPD perspective, because plasma levels of micronutrients are often influenced by an inflammatory state $^{(116)}$. Thus, longitudinal data are important for resolving uncertainty not just about the link between micronutrients and PPD, but also the link between micronutrients and biochemical markers of psychoneuroimmunological aetiology.

Third, observational research should stretch from early pregnancy to 1 year postpartum to identify when changes in micronutrient levels occur. This information would help prevention researchers time their interventions for presumed maximum effect.

Fourth, research needs to use a consistent method for monitoring micronutrient status. Dietary recall is not a preferred method for assessing micronutrient status, as it builds uncertainty into the study design. Using PUFA measurement as an example, validation studies for food questionnaires show that fish consumption as a measure of $n$-3 PUFA status only correlates with plasma measurements at the quartile level ${ }^{(117,118)}$. As an alternative, we recommend monitoring blood levels, which reflect the availability of micronutrients for biological processes. Blood sampling is, however, logistically difficult, and episodic sampling may need to be used in combination with dietary recall for a longitudinal study. Nonetheless, improved accuracy on micronutrient status is an important component of increasing the strength of study conclusions. In addition, blood sampling facilitates research on mechanisms of a micronutrient-PPD link. For example, measuring cytokine and cortisol levels at the same time allows investigation of a PNI of PPD hypothesis.

Fifth, to facilitate comparison of study results, research needs to use a common measurement tool and timeline for screening for PPD. We suggest a tool created specifically for postpartum populations, such as the EPDS ${ }^{(119)}$ or Postpartum Depression Screening Scale ${ }^{(120)}$. We recommend a timeline of PPD identified in the first 3 months postpartum.

We recognise that studies complying with all these suggestions will be difficult to carry out on a very large scale. There is a trade-off between large studies that can rigorously quantify the micronutrient-PPD relationship, and small studies that can investigate causal mechanisms for the relationship. As a result, it might be advisable 
to initiate moderately sized ( $n$ 1000) studies of the micronutrient-PPD relationship, focusing on specific populations or mechanisms of interest.

\section{Limitations}

One limitation of the present review is that the literature search was conducted only in the PubMed database and only included English-language articles. Another limitation is that the review did not establish level-of-evidence criteria for research results included in the analysis. Thus, the present review can provide only general direction to readers, unlike a systematic review that could provide a more solid foundation for research and clinical decisionmaking. A third limitation is that the present review's focus on physiological mechanisms resulted in some data not being included. For example, Strøm et al. ${ }^{(121)}$ conducted a large study on the relationship between $n$-3 PUFA or fish consumption and PPD. The authors measured PPD on the basis of (1) psychiatric admissions or (2) antidepressant prescriptions. These measures of PPD capture only the most severe cases, unlike depression-screening scales that are sensitive to developing or mild cases of PPD. The Strøm et al. data ${ }^{(121)}$ were not included in the present review because our focus on physiological contributors to PPD required the higher degree of sensitivity that screening scales provide.

To address these limitations, we recommend conducting a systematic review of articles related to the causal mechanisms for a micronutrient-PPD link. This review should include non-English publications. The review should also summarise data from studies that do not use a screening scale to measure the incidence of PPD

\section{Research significance}

At this time, evidence is not strong enough to safely prevent or treat PPD with dietary interventions or supplements alone. Further research on the link between micronutrients and PPD, specifically the PNI of PPD, is necessary before clinicians can design diet and supplementation plans to prevent and treat PPD. Currently, the American Psychiatric Association recommends a wide dosage range for $n-3$ PUFA treatment of mood disorders (from 1-9g EPA and DHA per $d$ ), with the EPA:DHA ratio undefined ${ }^{(122)}$. For $\mathrm{B}$ vitamins and trace minerals, there is no recommended dosage for mood disorders. Clarification of dosages for prevention or treatment of PPD might encourage more clinicians to treat pregnant and postpartum women with dietary modification or micronutrient supplements. These interventions would be relatively inexpensive, and women reluctant to take anti-depressant medication might be more willing to enter treatment ${ }^{(1,123-125)}$.

The potential association of micronutrients with PPD is also significant for health and agriculture policy. A demonstrated link between micronutrient status and PPD could be the basis for health education initiatives, including additional labelling of micronutrients in processed foods. Also, a demonstrated link could support inclusion of more micronutrient-rich foods in government benefit programmes, such as the Women, Infants, and Children nutritional support programme in the USA.

In conclusion, limited evidence suggests that certain micronutrient deficiencies may be factors causing some women to move beyond risk to develop PPD. How these deficiencies influence immune and HPA axis function is an intriguing direction for research from a PNI of PPD perspective.

\section{Acknowledgements}

The present review was supported in part by funding from the National Institutes of Health (R01NR011278).

E. R. E.-B. was the primary researcher and writer for this paper. E. J. C. oversaw the project and reviewed drafts when the paper was prepared for publication.

The authors declare no potential conflicts of interest for themselves or their institution.

\section{References}

1. Yonkers KA, Vigod S \& Ross LE (2011) Diagnosis, pathophysiology, and management of mood disorders in pregnant and postpartum women. Obstet Gynecol 117, 961-977.

2. Robertson E, Grace S \& Wallington T, et al. (2004) Antenatal risk factors for postpartum depression: a synthesis of recent literature. Gen Hosp Psychiatry 26, 289-295.

3. Corwin EJ, Johnston N \& Pugh L (2008) Symptoms of postpartum depression associated with elevated levels of interleukin- $1 \beta$ during the first month postpartum. Biol Res Nurs 10, 128-133.

4. Groer MW \& Morgan K (2007) Immune, health and endocrine characteristics of depressed postpartum mothers. Psychoneuroendocrinology 32, 133-139.

5. Bloch M, Rotenberg N, Koren D, et al. (2006) Risk factors for early postpartum depressive symptoms. Gen Hosp Psychiatry 28, 3-8.

6. Miller AH, Maletic V \& Raison CL (2009) Inflammation and its discontents: the role of cytokines in the pathophysiology of major depression. Biol Psychiatry 65, 732-741.

7. Dantzer R, O'Connor JC, Freund GG, et al. (2008) From inflammation to sickness and depression: when the immune system subjugates the brain. Nat Rev Neurosci 9 $46-56$.

8. Maes M, Ombelet W, De Jongh R, et al. (2001) The inflammatory response following delivery is amplified in women who previously suffered from major depression, suggesting that major depression is accompanied by a sensitization of the inflammatory response system. J Affect Disord 63, 85-92.

9. Maes M, Lin AH, Ombelet W, et al. (2000) Immune activation in the early puerperium is related to postpartum anxiety and depressive symptoms. Psychoneuroendocrinology 25, 121-137.

10. Browne M, Jacobs M, Lahiff M, et al. (2010) Perineal injury in nulliparous women giving birth at a community hospital reduced risk in births attended by certified nurse-midwives. J Midwifery Womens Health 55, 243-249. 
11. O'Brien J, Lyons T, Monks J, et al. (2010) Alternatively activated macrophages and collagen remodeling characterize the postpartum involuting mammary gland across species. Am J Pathol 176, 1241-1255.

12. Angioli R, Gómez-Marín O, Cantuaria G, et al. (2000) Severe perineal lacerations during vaginal delivery: the University of Miami experience. Am J Obstet Gynecol 182, 1083-1085.

13. Connolly AM \& Thorp JM (1999) Childbirth-related perineal trauma: clinical significance and prevention. Clin Obstet Gynecol 42, 820-835.

14. Bodnar LM \& Wisner KL (2005) Nutrition and depression: implications for improving mental health among childbearing-aged women. Biol Psychiatry 58, 679-685.

15. Murphy PK, Mueller M, Hulsey TC, et al. (2010) An exploratory study of postpartum depression and vitamin D. J Am Psychiatr Nurses Assoc 16, 170-177.

16. Koletzko B, Lien E, Agostoni C, et al. (2008) The roles of long-chain polyunsaturated fatty acids in pregnancy, lactation and infancy: review of current knowledge and consensus recommendations. J Perinat Med 36, 5-14.

17. Adkins Y \& Kelley DS (2010) Mechanisms underlying the cardioprotective effects of omega-3 polyunsaturated fatty acids. J Nutr Biochem 21, 781-792.

18. Zhao Y, Joshi-Barve S, Barve S, et al. (2004) Eicosapentaenoic acid prevents LPS-induced TNF- $\alpha$ expression by preventing NF-кB activation. J Am Coll Nutr 23, 71-78.

19. Vecchio AJ, Simmons DM \& Malkowski MG (2010) Structural basis of fatty acid substrate binding to cyclooxygenase-2. J Biol Chem 285, 22152-22163.

20. Saravanan P, Davidson NC, Schmidt EB, et al. (2010) Cardiovascular effects of marine omega-3 fatty acids. Lancet $\mathbf{3 7 6}$, 540-550.

21. Gleissman H, Johnsen JI \& Kogner P (2010) Omega-3 fatty acids in cancer, the protectors of good and the killers of evil? Exp Cell Res 316, 1365-1373.

22. Pestka JJ (2010) n-3 Polyunsaturated fatty acids and autoimmune-mediated glomerulonephritis. Prostaglandins Leukot Essent Fatty Acids 82, 251-258.

23. Harbige LS (2003) Fatty acids, the immune response, and autoimmunity: a question of $n-6$ essentiality and the balance between $n-6$ and $n$-3. Lipids 38, 323-341.

24. Liperoti R, Landi F, Fusco O, et al. (2009) Omega-3 polyunsaturated fatty acids and depression: a review of the evidence. Curr Pharm Des 15, 4165-4172.

25. Sontrop J \& Campbell MK (2006) Omega-3 polyunsaturated fatty acids and depression: a review of the evidence and a methodological critique. Prev Med 42, 4-13.

26. Lespérance F, Frasure-Smith N, St-André E, et al. (2011) The efficacy of omega-3 supplementation for major depression: a randomized controlled trial. J Clin Psychiatry 72, 1054-1062.

27. Rondanelli M, Giacosa A, Opizzi A, et al. (2010) Effect of omega-3 fatty acids supplementation on depressive symptoms and on health-related quality of life in the treatment of elderly women with depression: a double-blind, placebo-controlled, randomized clinical trial. J Am Coll Nutr 29, 55-64.

28. Nemets H, Nemets B, Apter A, et al. (2006) Omega-3 treatment of childhood depression: a controlled, double-blind pilot study. Am J Psychiatry 163, 1098-1100.

29. Su K-P, Huang S-Y, Chiu C-C, et al. (2003) Omega-3 fatty acids in major depressive disorder: a preliminary doubleblind, placebo-controlled trial. Eur Neuropsychopharmacol 13, 267-271.

30. Rogers PJ, Appleton KM, Kessler D, et al. (2008) No effect of $n-3$ long-chain polyunsaturated fatty acid (EPA and
DHA) supplementation on depressed mood and cognitive function: a randomised controlled trial. Br J Nutr 99, 421-431.

31. Silvers KM, Woolley CC, Hamilton FC, et al. (2005) Randomised double-blind placebo-controlled trial of fish oil in the treatment of depression. Prostaglandins Leukot Essent Fatty Acids 72, 211-218.

32. Marangell LB, Martinez JM, Zboyan HA, et al. (2003) A double-blind, placebo-controlled study of the omega-3 fatty acid docosahexaenoic acid in the treatment of major depression. Am J Psychiatry 160, 996-998.

33. Freeman MP, Hibbeln JR, Wisner KL, et al. (2006) Omega-3 fatty acids: evidence basis for treatment and future research in psychiatry. J Clin Psychiatry 67, 1954-1967.

34. Lu D-Y, Tsao Y-Y, Leung Y-M, et al. (2010) Docosahexaenoic acid suppresses neuroinflammatory responses and induces heme oxygenase- 1 expression in BV-2 microglia: implications of antidepressant effects for omega-3 fatty acids. Neuropsychopharmacology 35, 2238-2248.

35. Su K-P (2009) Biological mechanism of antidepressant effect of omega-3 fatty acids: how does fish oil act as a 'mind-body interface'? Neurosignals 17, 144-152.

36. Al MD, van Houwelingen AC, Kester AD, et al. (1995) Maternal essential fatty acid patterns during normal pregnancy and their relationship to the neonatal essential fatty acid status. Br J Nutr 74, 55-68.

37. Holman RT, Johnson SB \& Ogburn PL (1991) Deficiency of essential fatty acids and membrane fluidity during pregnancy and lactation. Proc Natl Acad Sci U S A 88, 4835-4839.

38. Otto SJ, Houwelingen AC, Antal M, et al. (1997) Maternal and neonatal essential fatty acid status in phospholipids: an international comparative study. Eur J Clin Nutr 51, $232-242$

39. Hibbeln JR (2002) Seafood consumption, the DHA content of mothers' milk and prevalence rates of postpartum depression: a cross-national, ecological analysis. I Affect Disord 69, 15-29.

40. De Vriese SR, Christophe AB \& Maes M (2003) Lowered serum $n-3$ polyunsaturated fatty acid (PUFA) levels predict the occurrence of postpartum depression: further evidence that lowered $n$-PUFAs are related to major depression. Life Sci 73, 3181-3187.

41. Makrides M, Crowther CA, Gibson RA, et al. (2003) Docosahexaenoic acid and post-partum depression - is there a link? Asia Pac J Clin Nutr 12, Suppl., S37.

42. Otto SJ, de Groot RHM \& Hornstra G (2003) Increased risk of postpartum depressive symptoms is associated with slower normalization after pregnancy of the functional docosahexaenoic acid status. Prostaglandins Leukot Essent Fatty Acids 69, 237-243.

43. Browne JC, Scott KM \& Silvers KM (2006) Fish consumption in pregnancy and omega-3 status after birth are not associated with postnatal depression. J Affect Disord 90, 131-139.

44. Miyake Y, Sasaki S, Yokoyama T, et al. (2006) Risk of postpartum depression in relation to dietary fish and fat intake in Japan: the Osaka Maternal and Child Health Study. Psychol Med 36, 1727-1735.

45. Llorente AM, Jensen CL, Voigt RG, et al. (2003) Effect of maternal docosahexaenoic acid supplementation on postpartum depression and information processing. Am J Obstet Gynecol 188, 1348-1353.

46. Doornbos B, van Goor SA, Dijck-Brouwer DAJ, et al. (2009) Supplementation of a low dose of DHA or DHA + AA does not prevent peripartum depressive symptoms in a small population based sample. Prog Neuropsychopharmacol Biol Psychiatry 33, 49-52. 
47. Mattes E, McCarthy S, Gong G, et al. (2009) Maternal mood scores in mid-pregnancy are related to aspects of neonatal immune function. Brain Behav Immun 23, 380-388.

48. Freeman MP, Davis M, Sinha P, et al. (2008) Omega-3 fatty acids and supportive psychotherapy for perinatal depression: a randomized placebo-controlled study. $J$ Affect Disord 110, 142-148.

49. Rees A-M, Austin M-P \& Parker GB (2008) Omega-3 fatty acids as a treatment for perinatal depression: randomized double-blind placebo-controlled trial. Aust N Z J Psychiatry 42, 199-205.

50. Makrides M, Gibson RA, McPhee AJ, et al. (2010) Effect of DHA supplementation during pregnancy on maternal depression and neurodevelopment of young children: a randomized controlled trial. JAMA 304, 1675-1683.

51. Su K-P, Huang S-Y, Chiu T-H, et al. (2008) Omega-3 fatty acids for major depressive disorder during pregnancy: results from a randomized, double-blind, placebo-controlled trial. J Clin Psychiatry 69, 644-651.

52. Freeman MP, Hibbeln JR, Wisner KL, et al. (2006) Randomized dose-ranging pilot trial of omega-3 fatty acids for postpartum depression. Acta Psychiatr Scand 113, 31-35.

53. Jans LAW, Giltay EJ \& Van der Does AJW (2010) The efficacy of $n$-3 fatty acids DHA and EPA (fish oil) for perinatal depression. Br J Nutr 104, 1577-1585.

54. Smulders YM \& Blom HJ (2011) The homocysteine controversy. J Inherit Metab Dis 34, 93-99.

55. Beydoun MA, Shroff MR, Beydoun HA, et al. (2010) Serum folate, vitamin B-12, and homocysteine and their association with depressive symptoms among U.S. adults. Psychosom Med 72, 862-873.

56. Malouf R \& Grimley Evans J (2003) The effect of vitamin $B_{6}$ on cognition. The Cochrane Database of Systematic Reviews 2003, issue 4, CD004393. http://www.mrw.interscience. wiley.com/cochrane/clsysrev/articles/CD004393/frame.html

57. Robinson D, O'Luanaigh C, Tehee E, et al. (2011) Associations between holotranscobalamin, vitamin $\mathrm{B}_{12}$, homocysteine and depressive symptoms in community-dwelling elders. Intl J Geriatr Psychiatry 26, 307-313.

58. Skarupski KA, Tangney C, Li H, et al. (2010) Longitudinal association of vitamin B-6, folate, and vitamin B-12 with depressive symptoms among older adults over time. $A m \mathrm{~J}$ Clin Nutr 92, 330-335.

59. Tiemeier H, van Tuijl HR, Hofman A, et al. (2002) Vitamin $\mathrm{B}_{12}$, folate, and homocysteine in depression: the Rotterdam Study. Am J Psychiatry 159, 2099-2101.

60. Murakami K, Miyake Y, Sasaki S, et al. (2010) Dietary folate, riboflavin, vitamin B-6, and vitamin B-12 and depressive symptoms in early adolescence: the Ryukyus Child Health Study. Psychosom Med 72, 763-768.

61. Almeida OP, Marsh K, Alfonso H, et al. (2010) B-vitamins reduce the long-term risk of depression after stroke: The VITATOPS-DEP trial. Ann Neurol 68, 503-510.

62. Fava M \& Mischoulon D (2009) Folate in depression: efficacy, safety, differences in formulations, and clinical issues. J Clin Psychiatry 70, Suppl. 5, 12-17.

63. Ford AH, Flicker L, Thomas J, et al. (2008) Vitamins $\mathrm{B}_{12}, \mathrm{~B}_{6}$, and folic acid for onset of depressive symptoms in older men: results from a 2-year placebo-controlled randomized trial. J Clin Psychiatry 69, 1203-1209.

64. Miyake Y, Sasaki S, Tanaka K, et al. (2006) Dietary folate and vitamins $\mathrm{B}_{12}, \mathrm{~B}_{6}$, and $\mathrm{B}_{2}$ intake and the risk of postpartum depression in Japan: the Osaka Maternal and Child Health Study. J Affect Disord 96, 133-138.

65. Rouillon F, Thalassinos M, Miller HD, et al. (1992) Folates and post partum depression. J Affect Disord 25, $235-241$.
66. Kesby JP, Eyles DW, Burne THJ, et al. (2011) The effects of vitamin $\mathrm{D}$ on brain development and adult brain function. Mol Cell Endocrinol 347, 121-127.

67. Borges MC, Martini LA \& Rogero MM (2011) Current perspectives on vitamin $\mathrm{D}$, immune system, and chronic diseases. Nutrition 27, 399-404.

68. Garcion E, Wion-Barbot N, Montero-Menei CN, et al. (2002) New clues about vitamin D functions in the nervous system. Trends Endocrinol Metab 13, 100-105.

69. Obradovic D, Gronemeyer H, Lutz B, et al. (2006) Crosstalk of vitamin $\mathrm{D}$ and glucocorticoids in hippocampal cells. J Neurochem 96, 500-509.

70. Lee DM, Tajar A, O'Neill TW, et al. (2011) Lower vitamin D levels are associated with depression among communitydwelling European men. $J$ Psychopharmacol 25 , 1320-1328.

71. Hoogendijk WJG, Lips P, Dik MG, et al. (2008) Depression is associated with decreased 25-hydroxyvitamin $\mathrm{D}$ and increased parathyroid hormone levels in older adults. Arch Gen Psychiatry 65, 508-512.

72. Jorde R, Waterloo K, Saleh F, et al. (2006) Neuropsychological function in relation to serum parathyroid hormone and serum 25-hydroxyvitamin D levels. The Troms $\varnothing$ study. J Neurol 253, 464-470.

73. Pan A, Lu L, Franco OH, et al. (2009) Association between depressive symptoms and 25-hydroxyvitamin D in middleaged and elderly Chinese. J Affect Disord 118, 240-243.

74. Eskandari F, Martinez PE, Torvik S, et al. (2007) Low bone mass in premenopausal women with depression. Arch Intern Med 167, 2329-2336.

75. Wilkins CH, Sheline YI, Roe CM, et al. (2006) Vitamin D deficiency is associated with low mood and worse cognitive performance in older adults. Am J Geriatr Psychiatry 14, 1032-1040.

76. Schneider B, Weber B, Frensch A, et al. (2000) Vitamin D in schizophrenia, major depression and alcoholism. J Neural Transm 107, 839-842.

77. Herrán A, Amado JA, García-Unzueta MT, et al. (2000) Increased bone remodeling in first-episode major depressive disorder. Psychosom Med 62, 779-782.

78. Michelson D, Stratakis C, Hill L, et al. (1996) Bone mineral density in women with depression. $N$ Engl J Med 335, 1176-1181.

79. Jorde R, Sneve M, Figenschau Y, et al. (2008) Effects of vitamin D supplementation on symptoms of depression in overweight and obese subjects: randomized double blind trial. I Intern Med 264, 599-609.

80. Sanders KM, Stuart AL, Williamson EJ, et al. (2011) Annual high-dose vitamin $\mathrm{D}_{3}$ and mental well-being: randomised controlled trial. Br J Psychiatry 198, 357-364.

81. Parker G \& Brotchie H (2011) 'D' for depression: any role for vitamin D? 'Food for Thought' II. Acta Psychiatr Scand 124, 243-249.

82. Bertone-Johnson ER (2009) Vitamin D and the occurrence of depression: causal association or circumstantial evidence? Nutr Rev 67, 481-492.

83. Fairweather-Tait SJ, Bao Y, Broadley MR, et al. (2011) Selenium in human health and disease. Antioxid Redox Signal 14, 1337-1383.

84. Maret W \& Sandstead HH (2006) Zinc requirements and the risks and benefits of zinc supplementation. J Trace Elem Med Biol 20, 3-18.

85. Prasad AS (2009) Zinc: role in immunity, oxidative stress and chronic inflammation. Curr Opin Clin Nutr Metab Care 12, 646-652.

86. Ibs K-H \& Rink L (2003) Zinc-altered immune function. J Nutr 133, 1452S-1456S. 
87. Prasad AS, Beck FWJ, Bao B, et al. (2008) Duration and severity of symptoms and levels of plasma interleukin-1 receptor antagonist, soluble tumor necrosis factor receptor, and adhesion molecules in patients with common cold treated with zinc acetate. $J$ Infect Dis 197, 795-802.

88. Beck FW, Prasad AS, Kaplan J, et al. (1997) Changes in cytokine production and $\mathrm{T}$ cell subpopulations in experimentally induced zinc-deficient humans. $\mathrm{Am} \mathrm{J}$ Physiol 272, E1002-E1007.

89. Fraker PJ \& King LE (2004) Reprogramming of the immune system during zinc deficiency. Annu Rev Nutr 24, 277-298.

90. Duntas LH (2009) Selenium and inflammation: underlying anti-inflammatory mechanisms. Horm Metab Res 41, 443-447.

91. Kiremidjian-Schumacher L, Roy M, Wishe HI, et al. (1994) Supplementation with selenium and human immune cell functions: effect on cytotoxic lymphocytes and natural killer cells. Biol Trace Elem Res 41, 115-127.

92. Hoffmann PR \& Berry MJ (2008) The influence of selenium on immune responses. Mol Nutr Food Res 52, $1273-1280$

93. Broome CS, McArdle F, Kyle JAM, et al. (2004) An increase in selenium intake improves immune function and poliovirus handling in adults with marginal selenium status. Am J Clin Nutr 80, 154-162.

94. Raucci R, Colonna G, Guerriero E, et al. (2011) Structural and functional studies of the human selenium binding protein-1 and its involvement in hepatocellular carcinoma. Biochim Biophys Acta 1814, 513-522.

95. Sanmartín C, Plano D, Font M, et al. (2011) Kinase regulation by sulfur and selenium containing compounds. Curr Cancer Drug Targets 11, 496-523.

96. Yang H, Fang J, Jia X, et al. (2011) Chemopreventive effects of early-stage and late-stage supplementation of vitamin $\mathrm{E}$ and selenium on esophageal carcinogenesis in rats maintained on a low vitamin E/selenium diet. Carcinogenesis 32, 381-388.

97. Brozmanová J, Mániková D, Vlčková V, et al. (2010) Selenium: a double-edged sword for defense and offence in cancer. Arch Toxicol 84, 919-938.

98. Jensen JD, Wing GJ \& Dellavalle RP (2010) Nutrition and melanoma prevention. Clin Dermatol 28, 644-649.

99. Sawada T \& Yokoi K (2010) Effect of zinc supplementation on mood states in young women: a pilot study. Eur J Clin Nutr 64, 331-333.

100. Maes M, D'Haese PC, Scharpé S, et al. (1994) Hypozincemia in depression. J Affect Disord 31, 135-140.

101. Marcellini F, Giuli C, Papa R, et al. (2006) Zinc status, psychological and nutritional assessment in old people recruited in five European countries: Zincage study. Biogerontology 7, 339-345.

102. DiGirolamo AM \& Ramirez-Zea M (2009) Role of zinc in maternal and child mental health. Am J Clin Nutr 89 940S-945S.

103. Nowak G, Siwek M, Dudek D, et al. (2003) Effect of zinc supplementation on antidepressant therapy in unipolar depression: a preliminary placebo-controlled study. Pol J Pharmacol 55, 1143-1147.

104. Szewczyk B, Poleszak E, Sowa-Kućma M, et al. (2008) Antidepressant activity of zinc and magnesium in view of the current hypotheses of antidepressant action. Pharmacol Rep 60, 588-589.

105. Tae WS, Kim SS, Lee KU, et al. (2011) Hippocampal shape deformation in female patients with unremitting major depressive disorder. Am J Neuroradiol 32, 671-676.
106. Benton D \& Cook R (1991) The impact of selenium supplementation on mood. Biol Psychiatry 29, 1092-1098.

107. Hawkes WC \& Hornbostel L (1996) Effects of dietary selenium on mood in healthy men living in a metabolic research unit. Biol Psychiatry 39, 121-128.

108. Finley J \& Penland J (1998) Adequacy or deprivation of dietary selenium in healthy men. J Trace Elem Exp Med 11, 11-27.

109. Rayman M, Thompson A, Warren-Perry M, et al. (2006) Impact of selenium on mood and quality of life: a randomized, controlled trial. Biol Psychiatry 59, 147-154.

110. Sher L (2001) Role of thyroid hormones in the effects of selenium on mood, behavior, and cognitive function. Med Hypotheses 57, 480-483.

111. Castaño A, Ayala A, Rodríguez-Gómez JA, et al. (1997) Low selenium diet increases the dopamine turnover in prefrontal cortex of the rat. Neurochem Int 30, 549-555.

112. Wójcik J, Dudek D, Schlegel-Zawadzka M, et al. (2006) Antepartum/postpartum depressive symptoms and serum zinc and magnesium levels. Pharmacol Rep 58, 571-576.

113. Maes M, Vandoolaeghe E, Neels H, et al. (1997) Lower serum zinc in major depression is a sensitive marker of treatment resistance and of the immune/inflammatory response in that illness. Biol Psychiatry 42, 349-358.

114. Mokhber N, Namjoo M, Tara F, et al. (2011) Effect of supplementation with selenium on postpartum depression: a randomized double-blind placebo-controlled trial. $J$ Matern Fetal Neonatal Med 24, 104-108.

115. Cheatham CL, Nerhammer AS, Asserhøj M, et al. (2011) Fish oil supplementation during lactation: effects on cognition and behavior at 7 years of age. Lipids $\mathbf{4 6}, 637-645$.

116. Duncan A, Talwar D, McMillan DC, et al. (2012) Quantitative data on the magnitude of the systemic inflammatory response and its effect on micronutrient status based on plasma measurements. Am J Clin Nutr 95, 64-71.

117. Lucas M, Asselin G, Mérette C, et al. (2009) Validation of an FFQ for evaluation of EPA and DHA intake. Public Health Nutr 12, 1783-1790.

118. Andersen LF, Solvoll K \& Drevon CA (1996) Very-long-chain $n-3$ fatty acids as biomarkers for intake of fish and $n-3$ fatty acid concentrates. Am J Clin Nutr 64, 305-311.

119. Cox JL, Holden JM \& Sagovsky R (1987) Detection of postnatal depression: development of the 10-item Edinburgh Postnatal Depression Scale. Br J Psychiatry 150, $782-786$

120. Beck CT \& Gable RK (2000) Postpartum Depression Screening Scale: development and psychometric testing. Nurs Res 49, 272-282.

121. Strøm M, Mortensen EL, Halldorsson TI, et al. (2009) Fish and long-chain $n$-3 polyunsaturated fatty acid intakes during pregnancy and risk of postpartum depression: a prospective study based on a large national birth cohort. Am J Clin Nutr 90, 149-155.

122. Freeman MP (2009) Omega-3 fatty acids in major depressive disorder. J Clin Psychiatry 70, Suppl. 5, 7-11.

123. Kendall-Tackett K (2010) Long-chain omega-3 fatty acids and women's mental health in the perinatal period and beyond. J Midwifery Womens Health 55, 561-567.

124. Leung BMY \& Kaplan BJ (2009) Perinatal depression: prevalence, risks, and the nutrition link - a review of the literature. J Am Diet Assoc 109, 1566-1575.

125. Turner KM, Sharp D, Folkes L, et al. (2008) Women's views and experiences of antidepressants as a treatment for postnatal depression: a qualitative study. Fam Pract 25, $450-455$. 